OPEN ACCESS

Edited by:

Jarrod Dudakov,

Fred Hutchinson Cancer Research

Center, United States

Reviewed by:

Tom Taghon,

Ghent University, Belgium

Jennifer Elizabeth Cowan,

National Institutes of Health (NIH),

United States

*Correspondence: Lucas C. M. Arruda

lucas.arruda@ki.se

Specialty section: This article was submitted to

T Cell Biology,

a section of the journal

Frontiers in Immunology

Received: 11 March 2020 Accepted: 26 May 2020

Published: 31 July 2020

Citation:

Gaballa A, Clave E, Uhlin M, Toubert A and Arruda LCM (2020) Evaluating

Thymic Function After Human

Hematopoietic Stem Cell

Transplantation in the Personalized

Medicine Era.

Front. Immunol. 11:1341

doi: 10.3389/fimmu.2020.01341

\section{Evaluating Thymic Function After Human Hematopoietic Stem Cell Transplantation in the Personalized Medicine Era}

\author{
Ahmed Gaballa ${ }^{1}$,Emmanuel Clave ${ }^{2,3}$, Michael Uhlin ${ }^{1,4,5}$, Antoine Toubert ${ }^{2,3}$ and \\ Lucas C. M. Arruda ${ }^{1 *}$ \\ ${ }^{1}$ Department of Clinical Science, Intervention and Technology, Karolinska Institutet, Stockholm, Sweden, ${ }^{2}$ INSERM \\ UMR-1160, Institut de Recherche Saint-Louis, Hôpital Saint-Louis APHP, Paris, France, ${ }^{3}$ Université de Paris, Paris, France, \\ ${ }^{4}$ Department of Applied Physics, Science for Life Laboratory, Royal Institute of Technology, Stockholm, Sweden, \\ ${ }^{5}$ Department of Clinical Immunology and Transfusion Medicine, Karolinska University Hospital, Stockholm, Sweden
}

Hematopoietic stem cell transplantation (HSCT) is an effective treatment option for several malignant and non-malignant hematological diseases. The clinical outcome of this procedure relies to a large extent on optimal recovery of adaptive immunity. In this regard, the thymus plays a central role as the primary site for de novo generation of functional, diverse, and immunocompetent T-lymphocytes. The thymus is exquisitely sensitive to several insults during HSCT, including conditioning drugs, corticosteroids, infections, and graft-vs.-host disease. Impaired thymic recovery has been clearly associated with increased risk of opportunistic infections and poor clinical outcomes in HSCT recipients. Therefore, better understanding of thymic function can provide valuable information for improving HSCT outcomes. Recent data have shown that, besides gender and age, a specific single-nucleotide polymorphism affects thymopoiesis and may also influence thymic output post-HSCT, suggesting that the time of precision medicine of thymic function has arrived. Here, we review the current knowledge about thymic role in HSCT and the recent work of genetic control of human thymopoiesis. We also discuss different transplant-related factors that have been associated with impaired thymic recovery and the use of T-cell receptor excision circles (TREC) to assess thymic output, including its clinical significance. Finally, we present therapeutic strategies that could boost thymic recovery post-HSCT.

Keywords: T-cells, thymus, hematopoietic stem cell transplantation, TREC, immune reconstitution, thymic function

\section{INTRODUCTION}

Hematopoietic stem cell transplantation (HSCT) represent the earliest form of stem cell therapy and has been used over six decades as treatment for several malignant and non-malignant blood conditions (1). Its clinical outcome relies on a successful immune recovery, particularly an optimal T-cell reconstitution. Following HSCT, innate immune cells recover in the initial weeks to months post-HSCT, while the T-cell pool recovery is accomplished through thymic-independent homeostatic proliferation of donor-derived mature T-cells in the 1st year (2). Thereafter, the thymic-dependent de novo generation of naïve T-cells from donor hematopoietic stem cells (HSCs) 
play an essential role for immune restoring in a process that can take years and is responsible for the full restoration of TCR specificities (3). The appropriate reconstitution of the Tcell compartment is of utmost importance not only to fight opportunistic pathogens but also to promote tumor control. A prolonged post-transplant immunodeficiency is still a hurdle associated with increased infection, secondary malignancies, relapse, and high mortality rates (3). The key role played by $\mathrm{T}$ cells have been highlighted by the efficacy of donor lymphocyte infusions (DLI) in controlling disease relapse and by several works on T-cell reconstitution $(4,5)$. T-cell reconstitution, as result of thymic rebound post-transplant, is therefore strictly related to HSCT success and will be the focus of this review.

\section{T-CELL RECONSTITUTION POST-HSCT}

The T-cell compartment recovery after transplantation occurs by two temporally and spatially distinct pathways. In the 1st weeks and months post-transplant, donor-derived, and remaining $\mathrm{T}$ cells not depleted by the conditioning regiment undergo peripheral expansion, comprising a thymic-independent $\mathrm{T}$ cell reconstitution (Figures 1A,B) (6). This mechanism of homeostatic proliferation, also called lymphopenia-induced proliferation, is dependent of homeostatic cytokines such as IL-2, IL-7, and IL-15 (7-9). This results in the preferential expansion of CD8+ memory $\mathrm{T}$ cells, a subpopulation more responsive to cytokines due to previous antigen experience (such as cytomegalovirus, CMV) (10). Although thymic-independent pathway serves as a short track for rapid replenishment of the virtually empty T-cell pool, the extent to which it contributes to protect against infection is rather limited due to skewness of the TCR repertoire $(11,12)$. Additionally, T cells undergoing intense homeostatic proliferation are dysfunctional (13), present short telomeres $(14,15)$, and are more prone to activationinduced cell death (13). This altogether contributes to an incomplete $\mathrm{T}$-cell reconstitution associated with high incidence of infections post-HSCT.

A complete reconstitution of the T-cell compartment depends on the thymic rebound and consequent de novo production of naïve $\mathrm{T}$ cells by the recipient thymus. Thymic-generated $\mathrm{T}$ cells undergo TCR rearrangement and stringent selection steps, resulting in a self-tolerant, highly diverse repertoire of polyfunctional $\mathrm{T}$ cells (3) (Figure 1C). This is supported by the seeding of the thymus with lymphoid progenitors arising from donor HSCs in constant maturation in the recipient's bone marrow (BM) (16). Within the thymus, T-cell progenitors undergo multi-differentiation steps and phenotypic changes, ultimately leading to the generation of a diverse repertoire of self-tolerant naïve $\mathrm{T}$ cells. These steps entail interactions between T-cell precursors (thymocytes), cortical thymic epithelial cells (cTECs), and stromal cells such as medullary TECs and dendritic cells $(17,18)$. This mechanism is tightly regulated and lead to the generation of naïve and MHC-restricted T-cells (CD4+, CD8+), with a non-self-antigen-specific TCR (19). Consequently, there is long-term immune recovery and complete T-cell reconstitution with high TCR specificities to several antigens that underlies infection control.

The thymus is a sensitive organ and suffer considerable damage during most HSCT protocols by the conditioning regimen and corticoids, and also post-transplant by infections and GvHD, leading to incomplete T-cell reconstitution and increased risk of infection and mortality (Figures 1A,D) (2). Regenerative therapies are under investigation to avoid thymic injury and to boost thymic output when appropriate (Figure 1E).

\section{SURROGATE MARKERS OF THYMIC OUTPUT: ADVANCES AND LIMITATIONS}

Understanding how the thymus contributes to T-cell reconstitution following HSCT has received considerable attention over the past years. Several efforts have been conducted to monitor thymic output, including assessment of thymic mass using computed tomography (20) and identifying recent thymic emigrants (RTE) using several phenotypic markers of naïve $\mathrm{T}$ cells (CD31+, CD45RA+) (21). Nevertheless, these methods either have provided semiquantitative estimates or were limited by their inability to distinguish between RTEs and long-lived naïve T cells $(22,23)$. TCR excision circles (TRECs) are stable episomal circular DNA fragments generated as by-products of TCR genes rearrangement and are exported from the thymus to the periphery within RTEs. Since the TCR $\delta$ locus is inserted within the TCR $\alpha$ locus, recombination of TCR $\alpha$ entails deletion of the TCR $\delta$ segment at a specific site that is common for $\sim 70 \%$ of thymocytes, resulting in $\delta \operatorname{Rec}-\Psi$ J $\alpha$ signal joint TRECs (sjTREC) and coding joint (cjTREC) (24, 25) (Figure 2A). sjTREC values reflect the thymic output of newly generated $\mathrm{T}$ cells and present a strong positive correlation with naïve CD4+, CD8+, and regulatory Tcells (26). Douek et al. (25) initially introduced TRECs as a reliable surrogate marker for thymic output in the context of HIV infection.

As result of the progress in molecular techniques, besides the advancement in HSCT and the growing interest in the thymic role post-HSCT, sjTREC quantification has become feasible for many researchers and has been extensively utilized for monitoring RTE in several studies $(3,27-31)$. However, it is of utmost importance to take into account that in the lymphopenic setting post-HSCT, the increase or decrease in sjTREC levels does not necessarily correlate to thymic output alone (32). In fact, sjTREC levels can be influenced by other external factors such as longevity and apoptosis of naïve T cells or degradation of the sjTREC itself (33). To take into account the issue of peripheral T-cell proliferation, Ki67 staining within naïve CD4+ T-cells together with TREC quantification has been proposed to more accurately model thymic output (34).

Given the potential limitation of using sjTREC alone, a Canadian-French group developed a novel method that depends on simultaneous quantification of TRECs generated at two different thymopoietic checkpoints. $\beta$ TREC is produced during $\mathrm{D} \beta \mathrm{J} \beta$ rearrangement at the $\mathrm{DN} 3$ stage and sjTREC generated at the DP stage (35). The estimation of $\beta$ TREC provides valuable information about intra-thymic proliferation that occurs between 


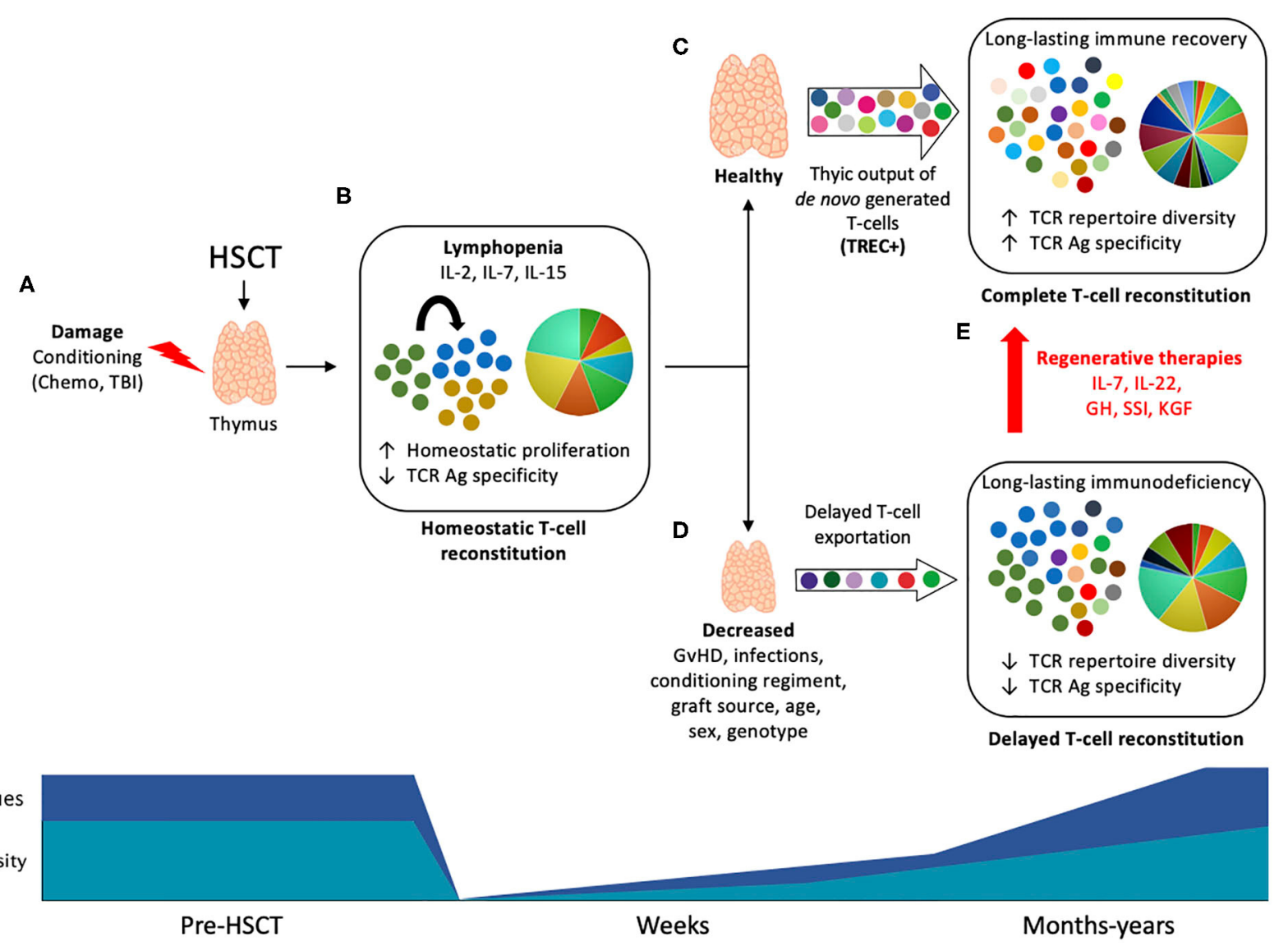

FIGURE 1 | Thymic function and T-cell reconstitution post-HSCT. Upper panel: (A) During HSCT, the thymus is subject to damage by the conditioning drugs, corticosteroids, and other agents used in transplantation protocol, leading to impaired function. (B) The profound lymphopenia that follows immunosuppression leads to homeostatic expansion of residual non-depleted T cells or donor cells driven by homeostatic cytokines (IL-2, IL-7, and IL-15), resulting in oligoclonal expansion and low TCR diversity. (C) Within few months post-HSCT, the thymus undergoes endogenous regeneration and start to export newly generated T cells that harbor TRECs. The production of self-tolerant T cells with a broader TCR repertoire will lead to a long-lasting immune recovery and to a complete T-cell reconstitution, associated with infections control and less HSCT-associated complications. (D) Depending on several patient- or HSCT protocol-associated causes, the reactivation of thymic function may be limited, leading to reduced TCR diversity and impaired T-cell reconstitution, associated with increased risk of infections and high mortality. (E) Thymic regenerative therapies may improve thymic function post-HSCT and promote complete T-cell reconstitution. Bottom panel: TREC values (dark blue) and TCR diversity (light blue) are reduced early after HSCT and slowly increase to baseline levels in a process that can take months to years as result of thymic rebound.

TCR $\beta$ - and TCR $\alpha$-chain rearrangements (36) (Figure 2A). Furthermore, the sj/ $\beta$ TREC ratio is not influenced by the dilution effect of peripheral proliferation (37). Despite the advantages of this method, it is labor intensive and time consuming which has limited its wide use. To overcome this, other researchers have developed more simplified methods for quantification of $\beta$ TREC $(36,37)$.

\section{FACTORS AFFECTING THYMIC FUNCTION POST-HSCT}

Restoration of the normal T-cell repertoire post-HSCT is a slow and long-term process that depends on the regenerative capacity of the thymus. The over-time exportation of TREC + RTEs results in an increased TCR repertoire diversity, that does not reach baseline values until months or even years post-HSCT
(Figure 1). Several parameters have been shown to influence thymic recovery following transplantation. Some of them are general, like the age, gender, and the genetic variation; while some others are transplant-specific such as conditioning, GvHD, and graft source. Here, we will briefly discuss some of these factors.

\section{General \\ Age}

Age-related thymic atrophy/involution is a physiologic process that has been described even before revealing the immunological function of the thymus itself. Thymic function reaches its peak by the 1st year of life and gradually declines thereafter (16). It has been postulated that thymic mass decreases by an annual rate of $3 \%$ until middle age, and subsequently by $1 \%$ per year (38). In the same way, recent data have described that sjTREC values present a decrease of about $4-5 \%$ per year (26), resulting in the subsequent reduction in of naïve T-cell counts. During 
A

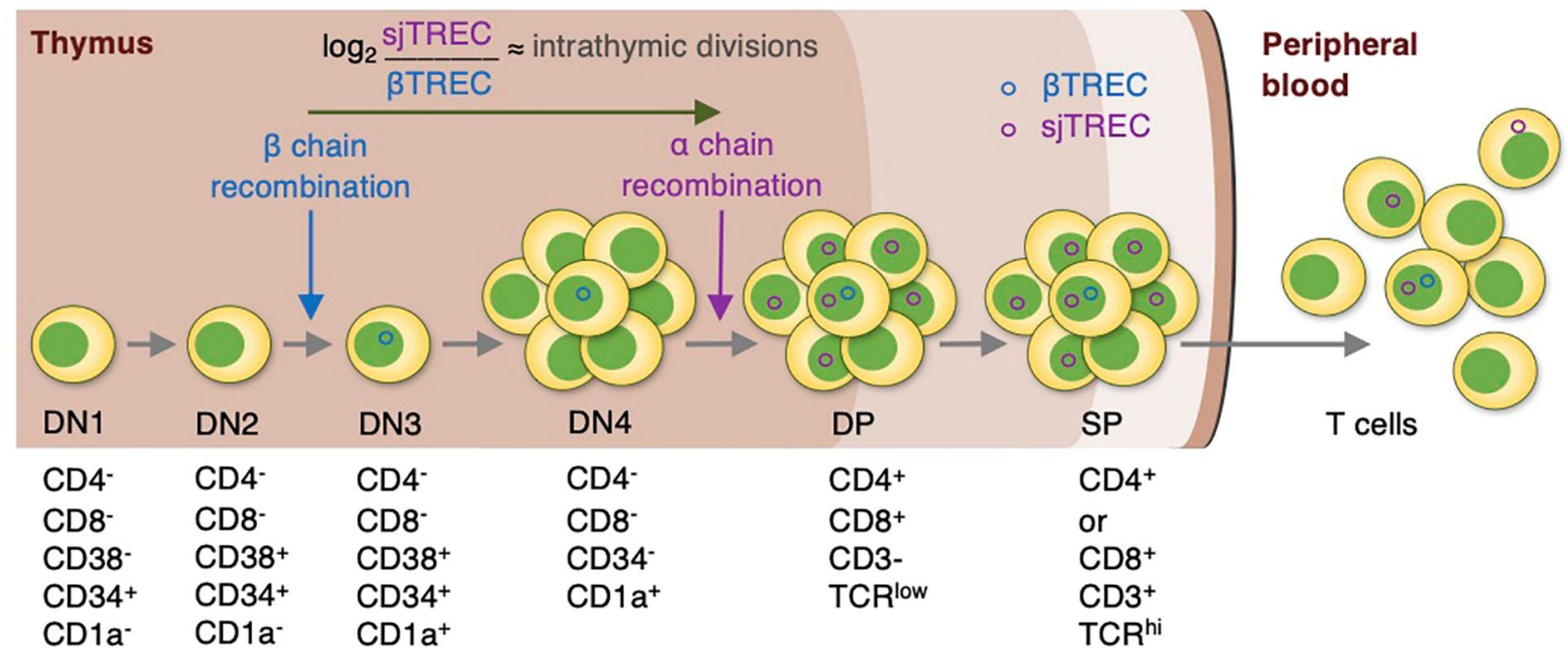

B

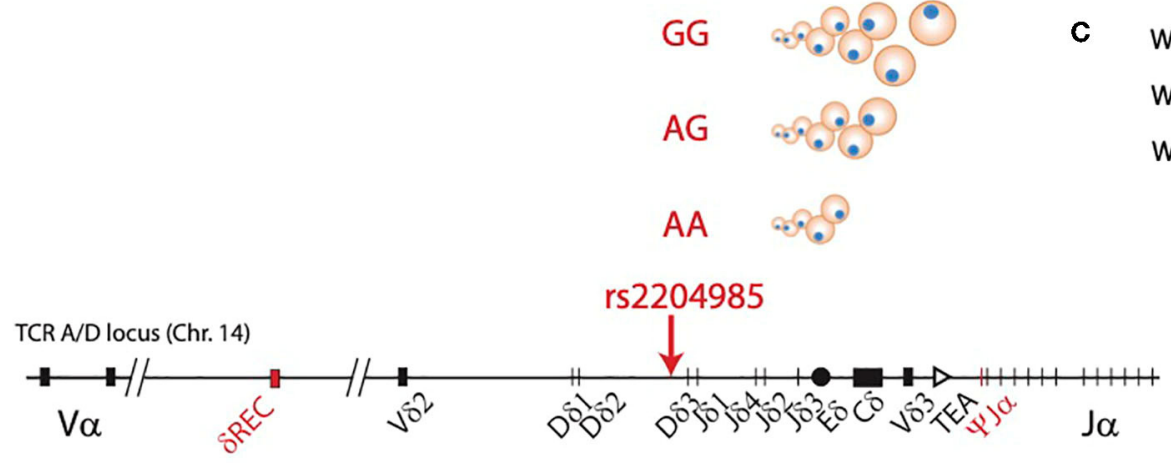

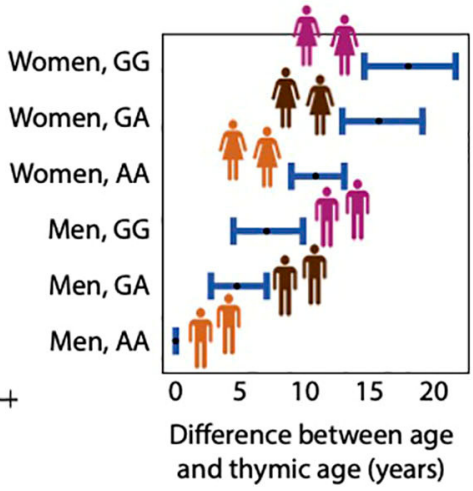

FIGURE 2 | Thymic function analysis by TREC and genetic control of thymopoiesis. (A) In the thymus, thymocytes undergo through positive and negative selections for self/non-self-education and cell maturation. During $\beta$-chain recombination, the non-replicative episomal DNA $\beta$ TREC arise from the TCRB locus excision and remain stable in the daughter cells. After differentiating and proliferating several times, thymocytes recombine the $\alpha$-chain, and excise the TCRA/D locus, generating the sjTREC. The ratio between sjTREC and $\beta$ TREC indicates the intrathymic proliferative activity of the thymocytes, once they remain conserved in the peripheral blood and directly reflect thymic function. (B) TREC values are influenced by genetic variation at the TCRA-TCRD locus, with the GG genotype at the genetic locus rs2204985 being associated with higher TREC numbers than AG and GG genotypes. (C) Difference between chronological age and thymic age as a function of sex and SNP rs2204985 variant. Thymic age was predicted from a regression model described in reference 26 , where the age of male carrying the AA genotype are assumed as the baseline.

involution, adipose tissue gradually replaces thymic stromal cells resulting in shrinkage in its size and progressive reduction in thymopoiesis, as shown in mice (39). This leads to the involution of thymic epithelial space and reduction of number of thymocytes due the increase of thymopoiesis-suppressive cytokines $(40,41)$. The reduction in IL-7 (42), impaired TCR $\beta$-chain rearrangement (43), alterations in hormones and growth factors, and changes in thymic niche have also been suggested as possible underlying mechanisms in rats and humans $(44,45)$. Of note, age-related involution does not lead to a complete loss of thymic function as residual thymic output can still be retained even in advanced ages, albeit significantly reduced (46). On this matter, age is an independent risk factor related to thymic function impairment in HSCT (47), with the thymic rebound post-HSCT shown to be reduced in elderly as compared to young adults and resulting in reduced naïve T-cells production (48).
Impaired immune reconstitution post-HSCT correlates with increased morbidity and mortality caused by infection and relapse $(3,49)$. Thus, is critical the development of strategies that enhance thymic output and immune reconstitution, particularly in elderly patients.

\section{Sex}

Apart from age, thymic output has also been linked to gender. Age-related thymic involution is higher in males compared to females (50) and testosterone treatment results in decreased thymic output (51). This was confirmed by two large population studies where the women presented $66-86 \%$ higher sjTREC values than men of all age ranges (26). It is therefore expected that women would have a better outcome post-HSCT with regards to infections and relapse due to the higher thymic function than men. In fact, recent data from a large cohort of 
around 12,000 patients have shown that recipient gender is an important prognostic factor independent of donor gender, with male recipients having inferior survival compared to females regardless of donor gender (52). This might partly be associated with the higher thymic function in females. Although a female recipient is beneficial, female donors to a male recipient has been shown to be deleterious, and a higher transplant-related mortality for male recipients of female allografts compared with other recipient-donor sex combinations was initially reported (53). Such observations led the European Group for Blood and Marrow Transplantation to include the female-to-male HSCT as a risk score, making male donors a safer choice for transplantation (54). This remark can result from the reduced thymic function in males, but it may also be due to the allogeneic response of female donor $\mathrm{T}$ cells toward minor histocompatibility antigens from male recipient (52).

\section{Genetic Factors}

Genetic background can also be implicated in determining the thymic function and the rate of thymic involution. In this regard, Clave et al. (26) have assessed the impact of 5,699,237 common single-nucleotide polymorphisms (SNPs) on sjTREC levels in a genome-wide association study of 1,000 patients from a Milieu Intérieur cohort. This revealed for the first time a common genetic variant (rs2204985) in a $25-\mathrm{kb}$ region within the TCRA-TCRD locus in the intergenic $\mathrm{D} \delta 2-\mathrm{D} \delta 3$ segments affecting thymic output (Figure 2B). This was further replicated in an independent cohort. In both cohorts, a 43 and $44 \%$ increase of sjTREC values in GG homozygotes was observed as compared to AA homozygotes, respectively (26). The impact of this SNP was further validated in immunodeficient mice transplanted with human donor HSCs carrying the GG, GA, or AA genotype. The GG genotype was associated with a higher sjTREC and TCR diversity compared to mice transplanted with AG and AA donor genotype. Thymic age based on TREC output was then predicted from a regression model taking into account age, sex, and this genetic variation. Accordingly, the thymic function of a 40-year-old female with a GG genotype would be the same as a 21.5-year-old male with the AA genotype (Figure 2C). This study has introduced a new concept of thymic age which accounts for age, gender, and genotype (26). Their results highlight the need for personalized medicine and can be of great significance particularly in donor selection for HSCT settings. Further studies are required to reveal the clinical relevance of this SNP post-HSCT.

\section{Transplant-Related \\ GvHD}

GvHD is a common complication post-HSCT. Although the skin, liver, gastrointestinal tract, and lung are the classical primary targeted organs, accumulating evidences also suggest the damage on the hematopoietic system $(55,56)$. Using sj/ßTREC quantifications, Clave et al. have shown a significant reduction in thymic output in patients with acute GvHD (aGvHD). However, this effect was transient in young patients, suggesting that aGvHD-induced insults are reversible in $<25$ years old patients and depend on the regenerative capacity of the thymus
(57). Consistent with their findings, we showed that sjTREC levels were not affected by aGvHD in a long-term followup study (58). Conversely, chronic GvHD was associated with decreased TREC levels regardless of disease resolution (58-60), suggesting a permanent irreversible insult. Divergent GvHD prophylaxis regimens are employed in different centers and have been suggested as possible underlying cause or long-term reduced thymic function. We then studied in a prospective randomized trial, the effect of different GvHD prophylaxis (cyclosporine/methotrexate vs. tacrolimus/sirolimus) on TREC levels post-HSCT. Results indicated no difference between the two arms of the study at any time point (60).

\section{Conditioning Regimen}

HSCT is preceded by cytoreductive conditioning regiments, with the aims of reducing malignant burden, avoiding graft rejection, and enhancing engraftment (61). The severity of toxicities associated with the conditioning varies according to the intensity of conditioning protocol used during HSCT. In contrast to reduced intensity conditioning (RIC), myeloablative conditioning (MAC) is associated with higher toxicity and organ damage $(61,62)$. Thus, it is reasonable to assume that patients receiving MAC are more prone to impaired thymopoeisis. Surprisingly, reports from several groups were inconsistent; while some studies showed rapid reconstitution in RIC recipients (63, 64), no difference or even delayed T-cell reconstitution in RIC recipients was shown by others $(57,65,66)$. This controversy can be justified by realizing that RIC is mainly indicated for elderly and patients with co-morbidities. Additionally, the combination of ATG and/or DLI with RIC regimen in some works can jeopardize the real effect of mild conditioning on thymic output. Randomized trials comparing the impact of different conditioning regimens on the thymic function is warranted.

\section{Graft Source}

HSCs source has also been shown to impact TREC values following HSCT. However, whether peripheral blood or BM is favorable for better thymic recovery is still elusive. We have earlier shown increased TREC levels in BM recipients early postHSCT $(60,67)$. Furthermore, in a recent retrospective study, we assessed TREC levels in 63 recipients after a median of 12 years post-HSCT. We found that TREC levels were higher in $\mathrm{BM}$ graft recipients, suggesting a beneficial role in the longterm (58). Despite other studies have not shown a significant association between TREC and stem cell graft source $(59,68)$, a higher engraftment and supportive thymic function is expected in BM grafts, which contain mesenchymal stromal cells and dendritic cells that can possibly engraft in the host after HSCT and support hematopoiesis.

\section{CLINICAL SIGNIFICANCE OF MONITORING THYMIC FUNCTION IN HSCT SETTING}

Monitoring thymic output in HSCT patients have significantly improved our understanding main issues related to HSCT and has allowed researchers to identify factors affecting 
thymic recovery post-HSCT. The association between pretransplantation TREC values and survival established thymic function to be a reliable predictor for morbidity and mortality $(3,69)$. Additionally, the clearance of CMV viremia and survival after umbilical cord blood (UCB) depends on a successful reconstitution of thymopoiesis $(70,71)$. In this regard, the monitoring of TREC levels in 331 samples from 158 allogeneic HSCT patients showed a strong correlation between low TREC levels and opportunistic infection in the first 6 months postHSCT (72). Moreover, low TREC levels post-HSCT has been associated with higher incidence of relapse (49). Similarly, results by Wils et al. (73) indicated a significant reduction in incidence of severe infections and lower risk of non-relapse mortality in patients who showed effective thymic recovery early postHSCT. In children undergoing T-cell depleted haploidentical HSCT, Clave et al. (74) showed that the incidence of leukemia relapse was found to be higher in patients who had undetectable $\beta$ TREC and low sjTREC levels post-HSCT. The same group has also reported similar findings in children who underwent UCB-HSCT (75). In a retrospective study, we earlier showed increased OS and decreased transplantation-related mortality in patient who had higher TREC levels at 3 months post-HSCT (67). In another study, we found high TREC levels post-HSCT to be associated with improved survival and decreased relapse incidence in leukemia patients (76). Corroborating with these results, Torlen et al. (60) reported reduced transplantationrelated mortality and increased 5-year OS in patients with high TREC levels in the first 6 months post-transplantation. Of note, the thymic rebound post-transplantation is associated with a favorable clinical response to autologous HSCT in autoimmune disease patients as well (71).

\section{BOOSTING THYMIC OUTPUT POST-HSCT}

Despite the thymus can spontaneously restore its function postHSCT, depending on recipient's age or repeated insults suffered during transplantation protocol, thymic regeneration might be impaired for long periods. Enhancing thymic function leading to efficient $\mathrm{T}$-cell reconstitution might be a promising route for future HSCT. In this regard, several strategies have been investigated yet so far only few have been successfully translated to the clinic (Figure 1E) (2).

Growth hormone $(\mathrm{GH})$ is one of the somatotropic hormones with a pivotal role in hematopoiesis. In a prospective randomized trial, Napolitano et al. investigated the impact of daily subcutaneous injections of rGH for 6 months on thymic function of HIV-infected patients. They demonstrated increased thymic output and TREC levels in treated patients (77). Corroborating with these findings, Hansen et al. (78) reported in a randomized placebo-controlled trial increase in thymic indices in HIV group treated by low dose $\mathrm{rGH}$. Although GH treatment has been used in children undergoing HSCT to treat post-radiation growth disorders $(79,80)$, its role in immune reconstitution has not so far been well-investigated.

The observation of rapid decline of thymic function with onset of puberty has suggested a role of sex hormones in thymic involution and set sex steroid inhibition (SSI) as a feasible strategy to restore immune competence in immunodeficient individuals (81). In fact, SSI surgically or pharmacologically has been associated with improved thymic function following HSCT in humans $(82,83)$, indicating that this approach can be used to boost thymic regeneration.

Keratinocyte growth factor (KGF) is produced by thymocytes and other stromal cells in the thymus and act inducing the expansion of epithelial cells. Several studies showed that administration of KGF alone or in combination with androgen blockade before HSCT is associated with improved regenerative capacity of the thymus and efficient T-cell reconstitution posttransplantation (84). Additionally, it has been shown that KGF protects TECs from the radiation-, conditioning-, and GvHDinduced damage in murine models (85-87), but its effects in humans are still elusive.

In addition to the above described strategies, several studies on murine models highlighted the role of IL-7, IL-21, IL-22, and zinc in restoring normal thymopoeisis $(42,88-93)$. In fact, rIL7 administration after human allogeneic T-cell depleted HSCT demonstrated an increase in T-cell recovery and increased TCR diversity, but no significant increase on thymic output was reported (94). Additionally, the advances in thymic organoids bioengineering technologies can provide a novel solution in the future $(95,96)$.

\section{CONCLUDING REMARKS}

The understanding of thymic function on HSCT outcomes have evolved tremendously in the last decades. Recently, the role of recipient age and sex and donor genotyping has been unrevealed as important factors associated with HSCT response, together with GvHD, conditioning regiment, and graft source. The remarkable finding that a donor genetic SNP affects strongly the recipient thymic output open a new era of graft selection (26), especially in cases when the recipient would benefit from an improved thymic function. Additionally, the recently published thymus cell atlas paved the way for a better understanding of human T-cell development and may impact HSCT research in the near future (97). The challenge for the next decades will be to translate these advances into a better donor selection and how to identify the proper recipient that should be treated with thymic boosters and which one to be used.

\section{AUTHOR CONTRIBUTIONS}

AG, EC, MU, AT, and LA prepared the figures, wrote the manuscript, and revised the final version. All authors contributed to the article and approved the submitted version.

\section{FUNDING}

This work was financed by grants from Karolinska Institutet, Stiftelsen Felix Mindus' contribution to leukemia research, Barncancerfonden, Radiumhemmets forskningsfonder, Cancerfonden, and David and Astrid Hagelén Foundation. 


\section{REFERENCES}

1. Chabannon C, Kuball J, Bondanza A, Dazzi F, Pedrazzoli P, Toubert A, et al. Hematopoietic stem cell transplantation in its 60s: a platform for cellular therapies. Sci Transl Med. (2018) 10:eaap9630. doi: 10.1126/scitranslmed.aap9630

2. Simons L, Cavazzana M, Andre I. Concise review: boosting Tcell reconstitution following allogeneic transplantation-current concepts and future perspectives. Stem Cells Transl Med. (2019) 8:650-7. doi: 10.1002/sctm.18-0248

3. Gaballa A, Sundin M, Stikvoort A, Abumaree M, Uzunel M, Sairafi D, et al. $\mathrm{T}$ cell receptor excision circle (TREC) monitoring after allogeneic stem cell transplantation; a predictive marker for complications and clinical outcome. Int J Mol Sci. (2016) 17:1705. doi: 10.3390/ijms17101705

4. Politikos I, Boussiotis VA. The role of the thymus in T-cell immune reconstitution after umbilical cord blood transplantation. Blood. (2014) 124:3201-11. doi: 10.1182/blood-2014-07-589176

5. Arruda LCM, Gaballa A, Uhlin M. Impact of gammadelta $T$ cells on clinical outcome of hematopoietic stem cell transplantation: systematic review and meta-analysis. Blood Adv. (2019) 3:343648. doi: 10.1182/bloodadvances.2019000682

6. Storek J, Zhao Z, Lin E, Berger T, McSweeney PA, Nash RA, et al. Recovery from and consequences of severe iatrogenic lymphopenia (induced to treat autoimmune diseases). Clin Immunol. (2004) 113:28598. doi: 10.1016/j.clim.2004.07.006

7. Schluns KS, Kieper WC, Jameson SC, Lefrancois L. Interleukin-7 mediates the homeostasis of naive and memory CD8 T cells in vivo. Nat Immunol. (2000) 1:426-32. doi: 10.1038/80868

8. Sandau MM, Winstead CJ, Jameson SC. IL-15 is required for sustained lymphopenia-driven proliferation and accumulation of CD8 T cells. $J$ Immunol. (2007) 179:120-5. doi: 10.4049/jimmunol.179.1.120

9. Thiant S, Moutuou MM, Leboeuf D, Guimond M. Homeostatic cytokines in immune reconstitution and graft-versus-host disease. Cytokine. (2016) 82:24-32. doi: 10.1016/j.cyto.2016.01.003

10. Tan JT, Ernst B, Kieper WC, LeRoy E, Sprent J, Surh CD. Interleukin (IL)15 and IL-7 jointly regulate homeostatic proliferation of memory phenotype CD8 + cells but are not required for memory phenotype CD4+ cells. J Exp Med. (2002) 195:1523-32. doi: 10.1084/jem.20020066

11. Mackall CL, Bare CV, Granger LA, Sharrow SO, Titus JA, Gress RE. Thymicindependent $\mathrm{T}$ cell regeneration occurs via antigen-driven expansion of peripheral $\mathrm{T}$ cells resulting in a repertoire that is limited in diversity and prone to skewing. J Immunol. (1996) 156:4609-16.

12. Mackall CL, Hakim FT, Gress RE. T-cell regeneration: all repertoires are not created equal. Immunol Today. (1997) 18:245-51. doi: 10.1016/S0167-5699(97)81664-7

13. Lin SJ, Peacock CD, Bahl K, Welsh RM. Programmed death-1 (PD-1) defines a transient and dysfunctional oligoclonal T cell population in acute homeostatic proliferation. J Exp Med. (2007) 204:2321-33. doi: 10.1084/jem.20062150

14. Ogonek J, Kralj Juric M, Ghimire S, Varanasi PR, Holler $\mathrm{E}$, Greinix $\mathrm{H}$, et al. Immune reconstitution after allogeneic hematopoietic stem cell transplantation. Front Immunol. (2016) 7:507. doi: 10.3389/fimmu.2016.00507

15. Arruda LCM, Lima-Junior JR, Clave E, Moraes DA, Douay C, Fournier I, et al. Homeostatic proliferation leads to telomere attrition and increased PD1 expression after autologous hematopoietic SCT for systemic sclerosis. Bone Marrow Transpl. (2018) 53:1319-27. doi: 10.1038/s41409-018-0162-0

16. Krenger W, Blazar BR, Hollander GA. Thymic T-cell development in allogeneic stem cell transplantation. Blood. (2011) 117:676876. doi: 10.1182/blood-2011-02-334623

17. Lopes N, Serge A, Ferrier P, Irla M. Thymic crosstalk coordinates medulla organization and T-cell tolerance induction. Front Immunol. (2015) 6:365. doi: 10.3389/fimmu.2015.00365

18. Zuniga-Pflucker JC. T-cell development made simple. Nat Rev Immunol. (2004) 4:67-72. doi: 10.1038/nri1257

19. Takaba H, Takayanagi $H$. The mechanisms of $\mathrm{T}$ cell selection in the thymus. Trends Immunol. (2017) 38:805-16. doi: 10.1016/j.it.2017. 07.010
20. Nasseri F, Eftekhari F. Clinical and radiologic review of the normal and abnormal thymus: pearls and pitfalls. Radiographics. (2010) 30:41328. doi: 10.1148/rg.302095131

21. Fink PJ. The biology of recent thymic emigrants. Annu Rev Immunol. (2013) 31:31-50. doi: 10.1146/annurev-immunol-032712-100010

22. Kohler S, Thiel A. Life after the thymus: CD31+ and CD31human naive CD4+ T-cell subsets. Blood. (2009) 113:76974. doi: 10.1182/blood-2008-02-139154

23. Junge S, Kloeckener-Gruissem B, Zufferey R, Keisker A, Salgo B, Fauchere JC, et al. Correlation between recent thymic emigrants and CD31+ (PECAM1) $\mathrm{CD} 4+\mathrm{T}$ cells in normal individuals during aging and in lymphopenic children. Eur J Immunol. (2007) 37:3270-80. doi: 10.1002/eji.200636976

24. Verschuren MC, Wolvers-Tettero IL, Breit TM, Noordzij J, van Wering ER, van Dongen JJ. Preferential rearrangements of the $\mathrm{T}$ cell receptor-deltadeleting elements in human T cells. J Immunol. (1997) 158:1208-16.

25. Douek DC, McFarland RD, Keiser PH, Gage EA, Massey JM, Haynes BF, et al. Changes in thymic function with age and during the treatment of HIV infection. Nature. (1998) 396:690-5. doi: 10.1038/25374

26. Clave E, Araujo IL, Alanio C, Patin E, Bergstedt J, Urrutia A, et al. Human thymopoiesis is influenced by a common genetic variant within the TCRA-TCRD locus. Sci Transl Med. (2018) 10:eaao2966. doi: 10.1126/scitranslmed.aao2966

27. Weinberg K, Blazar BR, Wagner JE, Agura E, Hill BJ, Smogorzewska M, et al. Factors affecting thymic function after allogeneic hematopoietic stem cell transplantation. Blood. (2001) 97:1458-66. doi: 10.1182/blood.V97.5.1458

28. Kohler S, Wagner U, Pierer M, Kimmig S, Oppmann B, Mowes B, et al. Post-thymic in vivo proliferation of naive CD4+ $\mathrm{T}$ cells constrains the TCR repertoire in healthy human adults. Eur J Immunol. (2005) 35:198794. doi: 10.1002/eji.200526181

29. Hochberg EP, Chillemi AC, Wu CJ, Neuberg D, Canning C, Hartman K, et al. Quantitation of T-cell neogenesis in vivo after allogeneic bone marrow transplantation in adults. Blood. (2001) 98:1116-21. doi: 10.1182/blood.V98.4.1116

30. Douek DC, Vescio RA, Betts MR, Brenchley JM, Hill BJ, Zhang L, et al. Assessment of thymic output in adults after haematopoietic stemcell transplantation and prediction of T-cell reconstitution. Lancet. (2000) 355:1875-81. doi: 10.1016/S0140-6736(00)02293-5

31. Hazenberg MD, Otto SA, de Pauw ES, Roelofs H, Fibbe WE, Hamann D, et al. T-cell receptor excision circle and T-cell dynamics after allogeneic stem cell transplantation are related to clinical events. Blood. (2002) 99:344953. doi: 10.1182/blood.V99.9.3449

32. Hazenberg MD, Verschuren MC, Hamann D, Miedema F, van Dongen JJ. T cell receptor excision circles as markers for recent thymic emigrants: basic aspects, technical approach, and guidelines for interpretation. J Mol Med (Berl). (2001) 79:631-40. doi: 10.1007/s001090100271

33. Hazenberg MD, Borghans JA, de Boer RJ, Miedema F. Thymic output: a bad TREC record. Nat Immunol. (2003) 4:97-9. doi: 10.1038/ni0203-97

34. Bains I, Thiebaut R, Yates AJ, Callard R. Quantifying thymic export: combining models of naive $\mathrm{T}$ cell proliferation and TCR excision circle dynamics gives an explicit measure of thymic output. J Immunol. (2009) 183:4329-36. doi: 10.4049/jimmunol.0900743

35. Dion ML, Poulin JF, Bordi R, Sylvestre M, Corsini R, Kettaf N, et al. HIV infection rapidly induces and maintains a substantial suppression of thymocyte proliferation. Immunity. (2004) 21:757-68. doi: 10.1016/j.immuni.2004.10.013

36. Ferrando-Martinez S, Franco JM, Ruiz-Mateos E, Hernandez A, Ordonez A, Gutierrez E, et al. A reliable and simplified sj/beta-TREC ratio quantification method for human thymic output measurement. J Immunol Methods. (2010) 352:111-7. doi: 10.1016/j.jim.2009.11.007

37. Ringhoffer S, Rojewski M, Dohner H, Bunjes D, Ringhoffer M. T-cell reconstitution after allogeneic stem cell transplantation: assessment by measurement of the sjTREC/betaTREC ratio and thymic naive $\mathrm{T}$ cells. Haematologica. (2013) 98:1600-8. doi: 10.3324/haematol.2012.072264

38. Gui J, Mustachio LM, Su DM, Craig RW. Thymus size and age-related thymic involution: early programming, sexual dimorphism, progenitors and stroma. Aging Dis. (2012) 3:280-90. Available online at: http://www.aginganddisease. org/EN/Y2012/V3/I3/280 
39. Yang H, Youm YH, Dixit VD. Inhibition of thymic adipogenesis by caloric restriction is coupled with reduction in age-related thymic involution. $J$ Immunol. (2009) 183:3040-52. doi: 10.4049/jimmunol.0900562

40. Sempowski GD, Hale LP, Sundy JS, Massey JM, Koup RA, Douek DC, et al. Leukemia inhibitory factor, oncostatin M, IL-6, and stem cell factor mRNA expression in human thymus increases with age and is associated with thymic atrophy. J Immunol. (2000) 164:2180-7. doi: 10.4049/jimmunol.164.4.2180

41. Lynch HE, Goldberg GL, Chidgey A, Van den Brink MR, Boyd R, Sempowski GD. Thymic involution and immune reconstitution. Trends Immunol. (2009) 30:366-73. doi: 10.1016/j.it.2009.04.003

42. Andrew D, Aspinall R. Age-associated thymic atrophy is linked to a decline in IL-7 production. Exp Gerontol. (2002) 37:45563. doi: 10.1016/S0531-5565(01)00213-3

43. Aspinall R. Age-associated thymic atrophy in the mouse is due to a deficiency affecting rearrangement of the TCR during intrathymic T cell development. $J$ Immunol. (1997) 158:3037-45.

44. Binz K, Joller P, Froesch P, Binz H, Zapf J, Froesch ER. Repopulation of the atrophied thymus in diabetic rats by insulin-like growth factor I. Proc Natl Acad Sci U S A. (1990) 87:3690-4. doi: 10.1073/pnas.87.10.3690

45. Ki S, Park D, Selden HJ, Seita J, Chung H, Kim J, et al. Global transcriptional profiling reveals distinct functions of thymic stromal subsets and age-related changes during thymic involution. Cell Rep. (2014) 9:40215. doi: 10.1016/j.celrep.2014.08.070

46. Mackall CL, Punt JA, Morgan P, Farr AG, Gress RE. Thymic function in young/old chimeras: substantial thymic $\mathrm{T}$ cell regenerative capacity despite irreversible age-associated thymic involution. Eur J Immunol. (1998) 28:188693. doi: 10.1002/(SICI)1521-4141(199806)28:06<1886::AID-IMMU1886>3. $0 . \mathrm{CO} ; 2-\mathrm{M}$

47. da Rocha LKA, Freschi de Barros S, Bandeira F, Bollini A, Testa LHA, Simione AJ, et al. Thymopoiesis in pre- and posthematopoietic stem cell transplantation. Front Immunol. (2018) 9:1889. doi: 10.3389/fimmu.2018.01889

48. Hakim FT, Memon SA, Cepeda R, Jones EC, Chow CK, Kasten-Sportes C, et al. Age-dependent incidence, time course, and consequences of thymic renewal in adults. J Clin Invest. (2005) 115:930-9. doi: 10.1172/JCI200522492

49. Mikhael NL, Elsorady M. Clinical significance of $\mathrm{T}$ cell receptor excision circle (TREC) quantitation after allogenic HSCT. Blood Res. (2019) 54:27481. doi: 10.5045/br.2019.54.4.274

50. Pido-Lopez J, Imami N, Aspinall R. Both age and gender affect thymic output: more recent thymic migrants in females than males as they age. Clin Exp Immunol. (2001) 125:409-13. doi: 10.1046/j.1365-2249.2001.01640.x

51. Olsen NJ, Kovacs WJ. Evidence that androgens modulate human thymic $\mathrm{T}$ cell output. J Investig Med. (2011) 59:32-5. doi: 10.2310/JIM.0b013e318200dc98

52. Kim HT, Zhang MJ, Woolfrey AE, St Martin A, Chen J, Saber W, et al. Donor and recipient sex in allogeneic stem cell transplantation: what really matters. Haematologica. (2016) 101:1260-6. doi: 10.3324/haematol.2016.147645

53. Gratwohl A, Hermans J, Niederwieser D, van Biezen A, van Houwelingen HC, Apperley J, et al. Female donors influence transplant-related mortality and relapse incidence in male recipients of sibling blood and marrow transplants. Hematol J. (2001) 2:363-70. doi: 10.1038/sj.thj.6200117

54. Gratwohl A, Stern M, Brand R, Apperley J, Baldomero H, de Witte T, et al. Risk score for outcome after allogeneic hematopoietic stem cell transplantation: a retrospective analysis. Cancer. (2009) 115:4715-26. doi: 10.1002/cncr.24531

55. Krenger W, Hollander GA. The immunopathology of thymic GVHD. Semin Immunopathol. (2008) 30:439-56. doi: 10.1007/s00281-008-0131-6

56. Gartner JG. Thymic involution with loss of Hassall's corpuscles mimicking thymic dysplasia in a child with transfusion-associated graft-versus-host disease. Pediatr Pathol. (1991) 11:449-56. doi: 10.3109/15513819109064780

57. Clave E, Busson M, Douay C, Peffault de Latour R, Berrou J, Rabian C, et al. Acute graft-versus-host disease transiently impairs thymic output in young patients after allogeneic hematopoietic stem cell transplantation. Blood. (2009) 113:6477-84. doi: 10.1182/blood-2008-09-176594

58. Gaballa A, Norberg A, Stikvoort A, Mattsson J, Sundberg B, Uzunel M, et al. Assessment of TREC, KREC and telomere length in long-term survivors after allogeneic HSCT: the role of GvHD and graft source and evidence for telomere homeostasis in young recipients. Bone Marrow Transpl. (2018) 53:69-77. doi: 10.1038/bmt.2017.216
59. Jimenez M, Martinez C, Ercilla G, Carreras E, Urbano-Ispizua A, Aymerich $\mathrm{M}$, et al. Clinical factors influencing T-cell receptor excision circle (TRECs) counts following allogeneic stem cell transplantation in adults. Transpl Immunol. (2006) 16:52-9. doi: 10.1016/j.trim.2006.02.006

60. Torlen J, Gaballa A, Remberger M, Mork LM, Sundberg B, Mattsson J, et al. Effect of graft-versus-host disease prophylaxis regimens on $\mathrm{T}$ and $\mathrm{B}$ cell reconstitution after allogeneic hematopoietic stem cell transplantation. Biol Blood Marrow Transpl. (2019) 25:1260-8. doi: 10.1016/j.bbmt.2019.01.029

61. Bacigalupo A, Ballen K, Rizzo D, Giralt S, Lazarus H, Ho V, et al. Defining the intensity of conditioning regimens: working definitions. Biol Blood Marrow Transpl. (2009) 15:1628-33. doi: 10.1016/j.bbmt.2009.07.004

62. Gyurkocza B, Sandmaier BM. Conditioning regimens for hematopoietic cell transplantation: one size does not fit all. Blood. (2014) 124:34453. doi: 10.1182/blood-2014-02-514778

63. Jimenez M, Martinez C, Ercilla G, Carreras E, Urbano-Ispizua A, Aymerich $\mathrm{M}$, et al. Reduced-intensity conditioning regimen preserves thymic function in the early period after hematopoietic stem cell transplantation. Exp Hematol. (2005) 33:1240-8. doi: 10.1016/j.exphem.2005.06.016

64. Chen X, Hale GA, Barfield R, Benaim E, Leung WH, Knowles J, et al. Rapid immune reconstitution after a reduced-intensity conditioning regimen and a CD3-depleted haploidentical stem cell graft for paediatric refractory haematological malignancies. Br J Haematol. (2006) 135:52432. doi: 10.1111/j.1365-2141.2006.06330.x

65. Federmann B, Hägele $M$, Pfeiffer $M$, Wirths $S$, Schumm $M$, Faul $\mathrm{C}$, et al. Immune reconstitution after haploidentical hematopoietic cell transplantation: impact of reduced intensity conditioning and CD3/CD19 depleted grafts. Leukemia. (2011) 25:121-9. doi: 10.1038/leu.2010.235

66. Maris $M$, Boeckh $M$, Storer $B$, Dawson $M$, White $K$, Keng $M$, et al. Immunologic recovery after hematopoietic cell transplantation with nonmyeloablative conditioning. Exp Hematol. (2003) 31:941-52. doi: 10.1016/S0301-472X(03)00201-7

67. Sairafi D, Mattsson J, Uhlin M, Uzunel M. Thymic function after allogeneic stem cell transplantation is dependent on graft source and predictive of long term survival. Clin Immunol. (2012) 142:343-50. doi: 10.1016/j.clim.2011.12.001

68. Fallen PR, McGreavey L, Madrigal JA, Potter M, Ethell M, Prentice HG, et al. Factors affecting reconstitution of the $\mathrm{T}$ cell compartment in allogeneic haematopoietic cell transplant recipients. Bone Marrow Transpl. (2003) 32:1001-14. doi: 10.1038/sj.bmt.1704235

69. Clave E, Rocha V, Talvensaari K, Busson M, Douay C, Appert ML, et al. Prognostic value of pretransplantation host thymic function in HLA-identical sibling hematopoietic stem cell transplantation. Blood. (2005) 105:260813. doi: 10.1182/blood-2004-04-1667

70. Brown JA, Stevenson K, Kim HT, Cutler C, Ballen K, McDonough S, et al. Clearance of CMV viremia and survival after double umbilical cord blood transplantation in adults depends on reconstitution of thymopoiesis. Blood. (2010) 115:4111-9. doi: 10.1182/blood-2009-09-244145

71. Arruda LCM, Malmegrim KCR, Lima-Junior JR, Clave E, Dias JBE, Moraes $\mathrm{DA}$, et al. Immune rebound associates with a favorable clinical response to autologous HSCT in systemic sclerosis patients. Blood Adv. (2018) 2:12641. doi: 10.1182/bloodadvances.2017011072

72. Lewin SR, Heller G, Zhang L, Rodrigues E, Skulsky E, van den Brink MR, et al. Direct evidence for new T-cell generation by patients after either T-celldepleted or unmodified allogeneic hematopoietic stem cell transplantations. Blood. (2002) 100:2235-42. doi: 10.1182/blood.V100.6.2235

73. Wils EJ, van der Holt B, Broers AE, Posthumus-van Sluijs SJ, Gratama JW, Braakman E, et al. Insufficient recovery of thymopoiesis predicts for opportunistic infections in allogeneic hematopoietic stem cell transplant recipients. Haematologica. (2011) 96:1846-54. doi: 10.3324/haematol.2011.047696

74. Clave E, Lisini D, Douay C, Giorgiani G, Busson M, Zecca M, et al. A low thymic function is associated with leukemia relapse in children given Tcell-depleted HLA-haploidentical stem cell transplantation. Leukemia. (2012) 26:1886-8. doi: 10.1038/leu.2012.59

75. Clave E, Lisini D, Douay C, Giorgiani G, Busson M, Zecca M, et al. Thymic function recovery after unrelated donor cord blood or T-cell depleted HLA-haploidentical stem cell transplantation correlates with 
leukemia relapse. Front Immunol. (2013) 4:54. doi: 10.3389/fimmu.2013.0 0054

76. Uzunel M, Sairafi D, Remberger M, Mattsson J, Uhlin M. T-cell receptor excision circle levels after allogeneic stem cell transplantation are predictive of relapse in patients with acute myeloid leukemia and myelodysplastic syndrome. Stem Cells Dev. (2014) 23:1559-67. doi: 10.1089/scd.201 3.0588

77. Napolitano LA, Schmidt D, Gotway MB, Ameli N, Filbert EL, Ng MM, et al. Growth hormone enhances thymic function in HIV-1-infected adults. J Clin Invest. (2008) 118:1085-98. doi: 10.1172/JCI32830

78. Hansen BR, Kolte L, Haugaard SB, Dirksen C, Jensen FK, Ryder LP, et al. Improved thymic index, density and output in HIV-infected patients following low-dose growth hormone therapy: a placebo controlled study. AIDS. (2009) 23:2123-31. doi: 10.1097/QAD.0b013e32833 03307

79. Bakker B, Oostdijk W, Geskus RB, Stokvis-Brantsma WH, Vossen JM, Wit JM. Growth hormone $(\mathrm{GH})$ secretion and response to GH therapy after total body irradiation and haematopoietic stem cell transplantation during childhood. Clin Endocrinol (Oxf). (2007) 67:589-97. doi: 10.1111/j.1365-2265.2007.02930.x

80. Isfan F, Kanold J, Merlin E, Contet A, Sirvent N, Rochette E, et al. Growth hormone treatment impact on growth rate and final height of patients who received HSCT with TBI or/and cranial irradiation in childhood: a report from the French Leukaemia Long-Term Follow-Up Study (LEA). Bone Marrow Transpl. (2012) 47:684-93. doi: 10.1038/bmt.2011.139

81. Velardi E, Dudakov JA, van den Brink MR. Sex steroid ablation: an immunoregenerative strategy for immunocompromised patients. Bone Marrow Transpl. (2015) 50(Suppl 2):S77-81. doi: 10.1038/bmt.2015.101

82. Goldberg GL, Sutherland JS, Hammet MV, Milton MK, Heng TS, Chidgey AP, et al. Sex steroid ablation enhances lymphoid recovery following autologous hematopoietic stem cell transplantation. Transplantation. (2005) 80:160413. doi: $10.1097 / 01 . t p .0000183962 .64777 . d a$

83. Heng TS, Goldberg GL, Gray DH, Sutherland JS, Chidgey AP, Boyd RL. Effects of castration on thymocyte development in two different models of thymic involution. J Immunol. (2005) 175:2982-93. doi: 10.4049/jimmunol.175.5.2982

84. Kelly RM, Highfill SL, Panoskaltsis-Mortari A, Taylor PA, Boyd RL, Hollander $\mathrm{GA}$, et al. Keratinocyte growth factor and androgen blockade work in concert to protect against conditioning regimen-induced thymic epithelial damage and enhance T-cell reconstitution after murine bone marrow transplantation. Blood. (2008) 111:5734-44. doi: 10.1182/blood-2008-01-136531

85. Erickson M, Morkowski S, Lehar S, Gillard G, Beers C, Dooley J, et al. Regulation of thymic epithelium by keratinocyte growth factor. Blood. (2002) 100:3269-78. doi: 10.1182/blood-2002-04-1036

86. Alpdogan O, Hubbard VM, Smith OM, Patel N, Lu S, Goldberg GL, et al. Keratinocyte growth factor (KGF) is required for postnatal thymic regeneration. Blood. (2006) 107:2453-60. doi: 10.1182/blood-2005-07-2831

87. Min D, Panoskaltsis-Mortari A, Kuro OM, Hollander GA, Blazar BR, Weinberg KI. Sustained thymopoiesis and improvement in functional immunity induced by exogenous KGF administration in murine models of aging. Blood. (2007) 109:2529-37. doi: 10.1182/blood-2006-08-043794

88. Wong CP, Song Y, Elias VD, Magnusson KR, Ho E. Zinc supplementation increases zinc status and thymopoiesis in aged mice. J Nutr. (2009) 139:13937. doi: 10.3945/jn.109.106021

89. Phillips JA, Brondstetter TI, English CA, Lee HE, Virts EL, Thoman ML. IL-7 gene therapy in aging restores early thymopoiesis without reversing involution. J Immunol. (2004) 173:4867-74. doi: 10.4049/jimmunol.173.8.4867

90. Rafei M, Dumont-Lagace M, Rouette A, Perreault C. Interleukin-21 accelerates thymic recovery from glucocorticoid-induced atrophy. PLoS One. (2013) 8:e72801. doi: 10.1371/journal.pone.0072801

91. Moretto MM, Hwang S, Chen K, Khan IA. Complex and multilayered role of IL-21 signaling during thymic development. J Immunol. (2019) 203:124251. doi: 10.4049/jimmunol.1800743

92. Tormo A, Khodayarian F, Cui Y, Al-Chami E, Kanjarawi R, Noe $\mathrm{B}$, et al. Interleukin-21 promotes thymopoiesis recovery following hematopoietic stem cell transplantation. J Hematol Oncol. (2017) 10:120. doi: 10.1186/s13045-017-0490-3

93. Pan B, Zhang F, Lu Z, Li L, Shang L, Xia F, et al. Donor T-cell-derived interleukin-22 promotes thymus regeneration and alleviates chronic graftversus-host disease in murine allogeneic hematopoietic cell transplant. Int Immunopharmacol. (2019) 67:194-201. doi: 10.1016/j.intimp.2018.12.023

94. Perales MA, Goldberg JD, Yuan J, Koehne G, Lechner L, Papadopoulos $\mathrm{EB}$, et al. Recombinant human interleukin-7 (CYT107) promotes T-cell recovery after allogeneic stem cell transplantation. Blood. (2012) 120:488291. doi: 10.1182/blood-2012-06-437236

95. Fan Y, Tajima A, Goh SK, Geng X, Gualtierotti G, Grupillo M, et al. Bioengineering thymus organoids to restore thymic function and induce donor-specific immune tolerance to allografts. Mol Ther. (2015) 23:126277. doi: $10.1038 / \mathrm{mt} .2015 .77$

96. Tajima A, Pradhan I, Geng X, Trucco M, Fan Y. Construction of thymus organoids from decellularized thymus scaffolds. Methods Mol Biol. (2019) 1576:33-42. doi: 10.1007/7651_2016_9

97. Park JE, Botting RA, Dominguez Conde C, Popescu DM, Lavaert M, Kunz DJ, et al. A cell atlas of human thymic development defines $\mathrm{T}$ cell repertoire formation. Science. (2020) 367:1-11. doi: 10.1101/2020.01.28.911115

Conflict of Interest: The authors declare that the research was conducted in the absence of any commercial or financial relationships that could be construed as a potential conflict of interest.

Copyright $\odot 2020$ Gaballa, Clave, Uhlin, Toubert and Arruda. This is an open-access article distributed under the terms of the Creative Commons Attribution License (CC $B Y)$. The use, distribution or reproduction in other forums is permitted, provided the original author(s) and the copyright owner(s) are credited and that the original publication in this journal is cited, in accordance with accepted academic practice. No use, distribution or reproduction is permitted which does not comply with these terms. 